\title{
Edible mushrooms of the Northwestern Himalaya, India: a study of indigenous knowledge, distribution and diversity
}

\author{
Semwal KC ${ }^{1}$, Stephenson $\mathrm{SL}^{2}$, Bhatt $\mathrm{VK}^{3}$, Bhatt $\mathbf{R P}^{4}$ \\ ${ }^{1}$ College of Natural and Computational Sciences, Department of Biology, Mekelle University, 3033, Mekelle, Tigray, \\ Ethiopia (East Africa) \\ ${ }^{2}$ Department of Biological Sciences, University of Arkansas, Fayetteville, Arkansas, 7270, USA \\ ${ }^{3}$ Navdanya, 105, Rajpur Road, Dehradun, Uttarakhand, India \\ ${ }^{4}$ Department of Botany, Hemwati Nandan Bahuguna Garhwal Central Universtiy, Sringagar, Garhwal, Uttarakhand, \\ India
}

Semwal KC, Stephenson SL, Bhatt VK, Bhatt RP 2014 - Edible mushrooms of the Northwestern Himalaya, India: a study of indigenous knowledge, distribution and diversity. Mycosphere 5(3), 440-461, Doi 10.5943/mycosphere/5/3/7

\begin{abstract}
In the present study, the diversity, edibility, indigenous knowledge and distribution of wild edible mushrooms in the Northwestern Himalaya are discussed. The information provided herein was derived from a study carried out in the states of Uttarakhand and Himachal Pradesh during the period of 2000-2013. A total of 23 species of mushrooms considered as edible or used for trade were recorded. Twenty-one of these are basidiomycetes and two are ascomycetes. Certain species of Amanita, Agaricus, Astraeus, Hericium, Macrolepiota, Morchella, Pleurotus and Termitomyces are very commonly collected and consumed by the local people, whereas species of Auricularia, Cantharellus, Sparassis, Lactarius, Ramaria and Russula are less commonly collected and consumed. Cordyceps sinensis and several species of Morchella are collected specifically for trade purposes in the spring season in high elevation areas of the Himalaya. Among the edible wild mushrooms collected are a number of species involved in ectomycorrhizal symbiotic relationships with banj (oak), other broadleaf trees and several types of conifers. The results of the present study can be used to promote the domestication of those wild edible mushrooms not yet cultivated in India. These results also indicate the need to avoid over exploitation of these mushrooms and a reason to establish a 'state germplasm bank' to allow studies of tissue culture. The latter could serve as the basis of further scientific study into various ways of enhancing the livelihood of particular areas of northern India through increased mushroom domestication as well as assessing the possible bioactivity of mushrooms against certain human diseases.
\end{abstract}

Key words - Ascomycetes - Basidiomycetes - Himachal Pradesh - Uttarakhand

\section{Introduction}

The history of the use of wild mushrooms as food and in medicine is well documented for many countries, and India is just one example (e.g., Kaul \& Kachroo 1974, Purkayastha \& Chandra 
1985, Sarkar et al. 1988, Bhatt \& Lakhanpal 1988, 1989, Sarkar 1988, Kaul 1993, Rai et al. 1993, Harsh et al. 1993, 1996, 1999, Boruah et al. 1996, Sharma \& Doshi 1996, Sharda et al. 1997, Barua et al.1998, Adhikary et al. 1999, Singh \& Rawat 2000, Boruah \& Singh 2001, Sagar et al. 2005, Sharma et al. 2009, Karwa 2010, Giri et al. 2012). In one of the more detailed accounts, a total of 30 different species of wild mushrooms were reported as being used by local villagers of West Bengal (Pradhan et al. 2010). However, reports that describe the collection of wild edible mushrooms are rather limited (e.g., Christensen \& Larsen 2005) or documented in papers published in less circulated journals. FAO (2004) stated that mushrooms are an important nutrient source in rural areas of India, and indicated that the species generally collected included members of the genera Termitomyces and Russula. Worldwide, an estimated 1,069 species of mushrooms have been reported as being used for food purposes (Boa 2004). For instance, on the African continent, most ethnic groups use wild mushrooms as food, and almost 300 species have been reported as consumed to some extent by humans (Rammeloo \& Walleyn 1993).

The Northwestern Himalaya of India encompasses the states of Uttarakhand $\left(28^{\circ} 43^{\prime} \mathrm{N}\right.$ to $31^{\circ} 28^{\prime} \mathrm{N}$ latitude and $77^{\circ} 34^{\prime} \mathrm{E}$ to $81^{\circ} 03^{\prime} \mathrm{E}$ longitude) and Himachal Pradesh (30 $22^{\circ}$ to $33^{\circ} 12^{\prime} \mathrm{N}$ latitude and $75^{\circ} 45^{\prime}$ to $79^{\circ} 04^{\prime}$ 'E longitude). Both Uttarakhand and Himachal Pradesh have extensive areas of forest cover (i.e., more than $50 \%$ of the total landscape). The three major forest types are coniferous forests, broadleaf forests and mixed forests. This region of northern India can be categorized broadly as having three seasons. These are the dry-summer season (April-June), warm rainy-season (July-September), and the winter cold-season (October-March). In coniferous forests, the major trees present are deodar (Cedrus deodara [Roxb.] G. Don., local name dayar and occurring over an elevation range of 2000 to $3000 \mathrm{~m}$ ); pine (Pinus roxburghii Sarg., local name cheed, chir or chil, 1200 to $2000 \mathrm{~m}$ ), blue pine (P. wallichiana A.B. Jackson, local name kail or cheeltu, 2100-2500 m), silver fir (Abies pindrow Royle, local name jhilla or rai, 2200-3600 m), spruce (Picea smithiana [Wall.] Boiss., local name tosh, 2400-3600 m), Himalayan yew (Taxus baccata L. subsp. wallichiana (Zucc.) Pilger, local names thuner, brami or rakhal, 2300-3300 m), Juniperus communis L. (local name hauber or bither, 2500-3300 m), and Cupressus torulosa D. Don ex Lamb., local name devidiyar, 2000-2600 m). In broadleaf forests the major components include several species of Quercus, Myrica (local name kaafal) and Rhododendron (local name burans or chio). The primary oaks are Quercus leucotrichophora A. Camus (local name banj, 1850-2300 m), Q. semecarpifolia Smith (local names kharsu or moharu, 2000-2500 m), Q. dilatata Lindle. ex Royle (local name moru, 2000-2500 m), Q. floribunda, Lindl. ex A. Camus (local name tilonz, 2000-2400 m) and Q. glauca Thunb. (local name banni, 2400-2700 m. The most important species of Rhododendron is the tree-sized $R$. arboreum Smith, common at elevations from 1800$2600 \mathrm{~m}$, whereas $R$. anthopogon D. Don (local name son pati or dhoop) and $R$. campanulatum D. Don local name brass or safed burans) are dwarf shrubs found in scattered localities in the high hills at elevations above $3000 \mathrm{~m}$. Other trees and shrubs found in the general study are Myrica esculenta Buch. Ham. ex. D. Don. (local name kaafal, 1850-2500 m), Lyonia ovalifolia (Wall.) (local name anyar, 1850-2200 m), Betula utilis D. Don (local name bhojpatra, 2500-3000 m), Aesculus indica (local name pangar or goon, 2300-2600 m), Cinnamomum tamala (local name daalchini or tejpatar, 1900-2400 m), Alnus neplensis D. Don. (local name piak, 2000-2500 m), Corylus jacquemontii (local name bhotia badam, 2100-2600 m) and Juglans regia L. (local name akhrot, 1750-2300 m). A mixed canopy composed of a mixture of such taxa as Cedrus, Cupressus, Pinus, Quercus, Rhododendron, Myrica, Lyonia, Alnus, Aesculus, Corylus, Cinnamomum and Betula is present in the high hills. In the lower hills Shorea robusta (local name sal, 400-1000 m) is mixed with Tectona grandis (local name sagon or teak), Mallotus philippensis (local name rohini) and Bauhinia malabarica (local name gular or kachnar).

\section{Ectomycorrhizal Associations}

Many of the trees listed above are recognized as establishing ectomycorrhizal associations with the mycelium of various mushrooms (Semwal 2003, 2005, 2006, 2008). This symbiotic relationship indicates that this fungus component of the forest ecosystem is essential to the health 
of the forest itself. However, these forests appear to be suffering from such adverse factors as global climate change and an apparent increased susceptibility to various insect pests. In light of these problems, it has become more important to make wise use of wild mushrooms in two waysto promote growth of seedlings in a tree nursery and as food for humans. Many studies have shown that the ectomycorrhizal association enhances the growth and even productivity of the mushroom flora of a region (Smiley et al. 1997). For example, early formation of the sporocarp in the gymnosperm Gnetum is enhanced by the presence of Scleroderma sinnamariense, which forms an ectomycorrhizal association with this plant (Ingleby 1999).

\section{Mushroom Hunting}

The northwest Himalaya receives an ample amount of rain during the rainy (monsoon) season that typically occurs from mid-June until mid- September. The range of precipitation in the region varies from 600 to $3200 \mathrm{~mm}$ during the monsoon season, when local people begin to search for valuable edible and medicinal mushrooms. Among those most commonly collected are species of Amanita, Astraeus, Cantherellus, Cordyceps, Morchella, Termitomyces, Pleurotus, Russula and Lactarius. Local people use wild mushrooms not only for food but also as a source of income by offering them for sale in local markets. For example, morels (Morchella spp., local name guchhi, Figs. 4B, F) are collected in the high hills and Astraeus (local name phutphut, Figs. 3C, G) from the lower hill regions, both to be sold in local or outside markets.

\section{Indigenous Beliefs Relating to the Uses of Wild Mushrooms}

In Uttarakhand and Himachal Pradesh, villagers tend to be either mycophilic (term applied to those ethnic groups in which wild mushroom are regarded as suitable food) and mycophobic (term applied to those ethnic groups that have only a minor regard for mushrooms and often have a fear of them) as described by Wasson and Wasson (1957). However, in the Northwestern Himalaya there is not a distinct culture which displays these exact phenomena, and both attitudes are present in the villages, sometimes even in the same family. This is due to the fact that some edible mushrooms are very similar in appearance to poisonous kinds and may even occur in the same habitat. One other important fact that emerged during our investigation is that in Hindu cultures most of the Brahmins (one of the ethnic groups in the Hindu religion) do not include animal flesh in their diet. They are pure vegetarians and assume that the taste of mushrooms (locally called chuein) is similar to the taste of animal flesh. For this reason, they don't use wild mushroom as food, even cultivated forms such as the button mushroom or the oyster mushroom (dhingri), both of which are often available in local markets. Another common myth held by many people is that all wild mushrooms are tested by snakes, so that the mushroom is rendered poisonous. Some people even think that since mushrooms occur normally in dirty places, they are unhygienic.

However, the lack of knowledge or confidence in making a correct identification of edible and poisonous mushrooms causes many casualties in the Northwestern Himalaya, but at the same time local people frequently have used wild mushrooms as food with no ill effects. They understand that a particular mushroom is poisonous because someone ate it and then became ill or died. There is no exact test or characteristic to distinguish edible from poisonous mushrooms. Almost every year some incidents of poisoning are reported from Uttarakhand and Himachal Himalaya in local newspapers, but to date no scientific investigations have ever been carried out to recognize these wild edible and poisonous mushrooms, either by the local government or by scientists working on wild mushrooms. There are several reasons that account for this situation. Often, when a mushroom poisoning incident takes place, it is in a remote area. Moreover, many incidents take place during the rainy season, when most of the approach roads, whether consisting of soil-stone or hot mixed charcoal, are damaged due to rain. As a result, victims do not reach a hospital on time. As such, simply getting to remote areas soon enough after the incident to take the sample required to identify the wild mushrooms responsible is difficult if not impossible.

With respect to the medicinal use of wild mushrooms in the Pauri region of Uttarakhand, the first author was fortunate to learn something about this when he was about 14 years old. The 
owner of the house in which his family lived was a traditional healer or practitioner (in local dialects, these people are known as vaidya), especially for illnesses involving children. He brought in certain fungi from the nearby areas of agricultural cropland, including some that fruited on cow dung. He used to make some type of decoction from these fungi and mixed this with some other local medicine and then prescribed for a child ill with certain types of diseases. Unfortunately, when the author grew up and ultimately earned a Ph.D., he was unable to learn anything about these fungi because the particular vaidya had died. There was no written evidence for the use of these mushrooms, so their possible medicinal values were never discovered. The first author still remembers the general appearance of the fruit bodies, which were small, deliquescent and brownish to blackish. It seems likely that the fruiting bodies were those of a species in the family Coprinaceae, since they were associated with dung and some mushrooms in this family are renowned for their psychoactive properties. In one other incident that took place somewhat later, a friend of the first author used to bring in some wild mushrooms from a pine forest in the Pauri Garhwal region of Uttarakhand to eat, and these mushrooms could have been Tricholoma matsutake. However, this species has not yet been reported from the Northwest Himalaya.

Much of what were once regarded as appropriate uses of wild mushrooms in the Northwestern Himalaya was never documented by science and this information vanished with the death of traditional healers or practitioners. Unfortunately, this is also true for the medicinal uses of plants in the general study area. The local names used for many of the wild mushrooms found in the Northwestern Himalaya suggest that they have been in use for a very long time. In the local language (Garhwali) of the people of Uttarakhand, bakri-cheun is the name used for species of Hericium because the fungus in question has the general appearance of the beard of a goat (bakri= goat and cheun = mushroom), ungli-cheun is the name given to Ramaria because the fruit bodies look like human fingers (ungli = finger and cheun $=$ mushroom), til-cheun is used for Tricholoma, gober-cheun for coprophilous fungi (gober = dung and cheun for mushroom), shinghani for Termitomyces, keeda ghas or keeda-jari for species of Cordyceps (keeda $=$ insect, ghas $=$ grass and jari = herb), b-mata ki tokri (basket of goddess) for Cyathus, dharti ka phool (flower of earth) for species of Macrolepiota, ekul-veer (standing alone warrior) for Amanita chepangiana, ghundaphodh for puffballs, peela phool for Cantharellus cibarius and guchhi for morels. In Himachal Pradesh, the words used for various fungi in the Pahadi language include shuntu for species of Ramaria, kanchantu for species of Helvella, chhatri for species of Lactarius, buthu for puffballs, zhanda for species of Rhizopogan and chunchuroo for morels. In the local dialect, only these names are used.

Mushrooms are a rich source of natural antibiotics. The glucans found in the cell wall are well known for their immunomodulatory properties, and the secondary metabolites have been found to be active against bacteria (Kupra et al. 1979) and viruses (Suzuki et al. 1990). Exudates from mushroom mycelia are active against protozoans such as the malaria parasite Plasmodium falciparum (Isaka et al. 2001). In general, humans and fungi share common microbial antagonists such as Staphylococcus aureus, Escherichia coli, and Pseudomonas aeruginosa, so humans can benefit from the natural defense strategies of fungi to produce antimicrobials (Hardman et al. 2001). It is known that polypores provide a protective immunological shield against a variety of infectious diseases (Hobbs 1986, Mizuno et al. 1995). As such, there is a great need to exploit these wild occurring mushrooms from the dense and well expended forests of Northwestern Himalaya to new drug discovery.

The purpose of this paper is to begin the process of documenting the wild edible and medicinal fungi in two states of India as to their cultural value. This documentation can be used as a resource (1) to cultivate new wild edible mushrooms to enhance the chances of improving the economy of the local villagers, farmers as well as the entire state and (2) to maintain the health of forests, since many wild mushroom are involved in the formation of ectomycorrhizal associations with the rootlets of the trees, with both partners in the relationship helping each other in many different ways. In the present paper a list of species is provided, along with their semi-technical descriptions and ways in which these fungi are used by local people. However, it is important to 
note that the list should not be regarded as a definitive taxonomic checklist, and some names must be considered as sensu lato until the species involved have been subjected to more detailed study. Moreover, some species are already described from the general study area or are to be described in forthcoming publications. The semi-technical descriptions are provided herein for the proper identification of particular species.

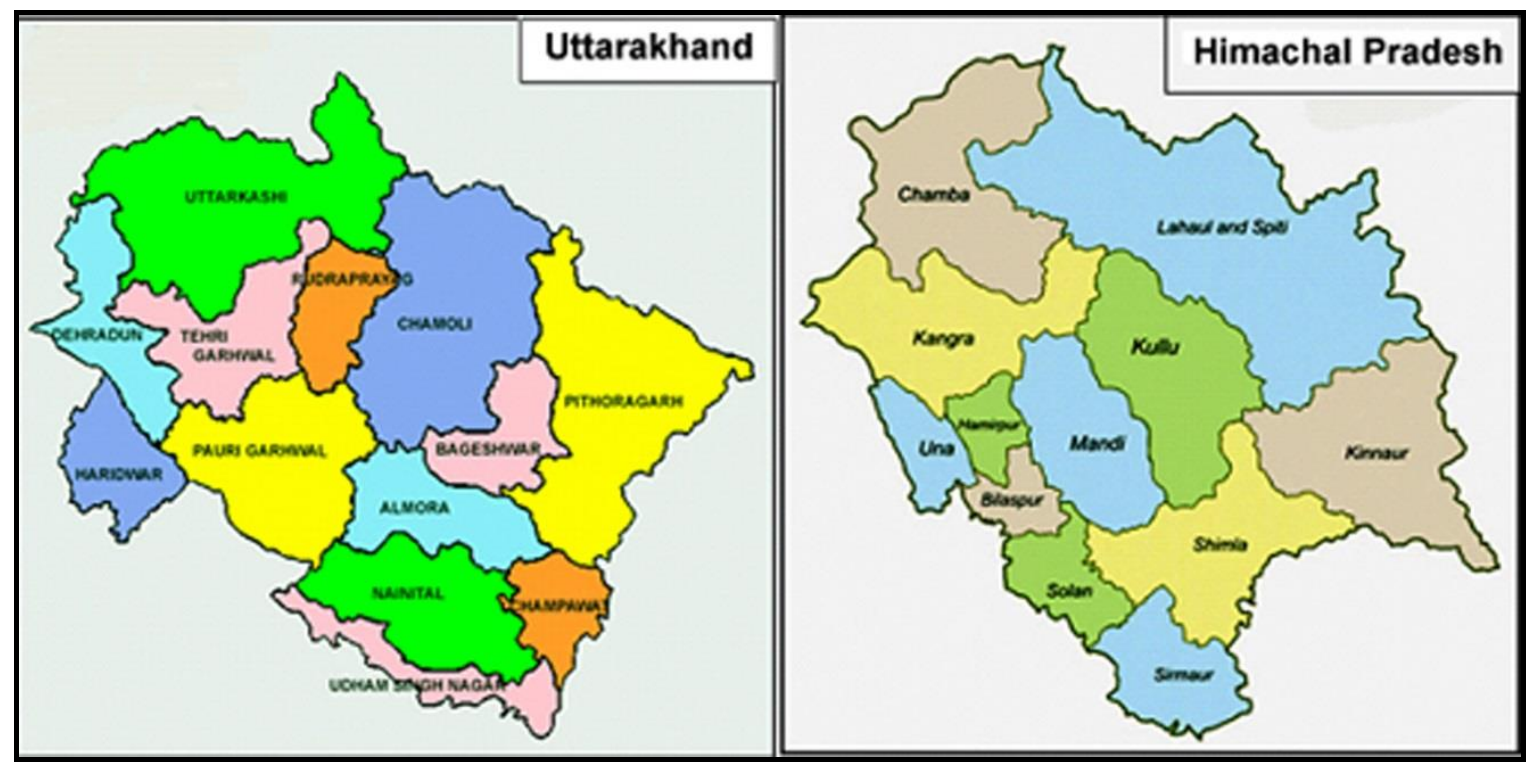

Figure 1 - Maps showing the states of Uttarakhand (left) and Himachal Pradesh (right) in the Northwestern Himalaya.

\section{Materials \& Methods}

This survey was carried out during the period of 2000 to 2013 for the purpose of gathering information about the uses of wild mushrooms in the Northwestern states of Uttarakhand and Himachal Pradesh in India. The focus of the study was on the different aspects of wild mushrooms as they relate to the local people. These include collection, consumption, identification and commodity use. In addition, information was compiled on the description, diversity, distribution and conservation aspects of the mushrooms in question. Data were collected through interviews and discussions with local villagers engaged in the collecting and eating of mushrooms, local residents, street-vendors and wholesale shopkeepers. The respondents were asked questions on the spot using a structured questionnaire seeking input of their perceptions about wild mushroom, how they identify a particular species, when and where from it can be collected, and how to clean, dry, sell and prepare it for human consumption.

Wild mushrooms were handled carefully to record macroscopic features used for identification. Ecological data also were collected to document the distribution of each species, along with photographs of fruit bodies in their natural habitat and field notes relating to possible host plants and the situations in which fruit bodies were found. Fruit bodies were brought to the laboratory, studied in detail and then dried in a hot air drier at $40^{\circ} \mathrm{C}$. Identifications were made with the use of various relevant monographs and other publications (e.g., Arora 1986, Singer 1986, Binion et al. 2008, Phillips 2010).

A number of mushrooms actually consumed by the first author in order to assess their taste just after being collected from the forests by the local people were Amanita hemibapha, A. chepangiana, Auricularia spp., Cantharellus cibarius, C. minor, Hericium erinaceus, Macrolepiota procera, Morchella spp., Pleurotus cornucopiae and Astraeus hygrometricus.

\section{Results \& Discussion}

The species of mushrooms recorded as edible and/or medicinal in the present study are listed in the section that follows. For each species, a short description is provided, along with 
information on ecological distribution, habitat, notes relating to the folklore associated with the mushroom in question and clues used for identification.

\section{Basidiomycetes}

Amanita hemibapha (Berk. \& Broome) Sacc. sensu lato, Syll. Fung. (Abellini) 5: 13 (1887)

Figs. 2A, B, D

Common name: Caesar's mushroom

Description: Fruit body medium to large, cap 7.0-18.5 cm wide, hemispherical to convex, plane with age, deep orange to orange red, deep yellow to yellowish, smooth, with a tuberculatesulcate striate margin, dry but viscid when wet. Gills free, of various lengths, truncate, pastel yellow to yellowish. Stipe 10-18 x 1.5-3 cm, yellowish orange to deep yellow, with appressed zigzag arranged fibrils, annulus superior, consistency thin to thick. Volva saccate, 4-7 x 2-4 cm, often with limbs, thick, flesh soft, pale yellow. Odor pleasant.

Habitat: Terrestrial, growing under various trees, widely distributed and very common from $900 \mathrm{~m}$ to $2800 \mathrm{~m}$ elevation in the Northwestern Himalaya. This is an ectomycorrhizal species that forms a symbiotic relationship with such trees as Shorea robusta and Tectona grandis in the lower hills; with Pinus roxburghii, Quercus leocotrichophora, Lyonia ovalifolia, Myrica esculaneta, Rhododendron arboretum and Aesculus indica (Semwal 2003) in the middle hills; and with Cedrus deodara, Abies pindrow, Picea smithiana, Cupressus torulosa, $Q$. semecarpifolia, $Q$. dilatata and Betula utilis in high-elevation forests. Amanita hemibapha is capable of establishing a symbiotic relationship with a wide range of trees and thus is similar in this respect to A. vaginata. It is often associated with Monotropa unifora, an achlorophyllous plant commonly known as Indian pipe (Fig 2C) and that derives its nutrition from fungal mycelia and the rootlets of trees in oakdominated forests of Phedkhal (Khirsu) and in the high-elevation forests of Jakholi (mixed woodlands) and Mandal (a mixed forest with oak, birch and Cedrus) in the Uttarakhand Himalaya. Amanita hemibapha is one of the fairly edible mushrooms in a group that also contains a number of deadly poisonous species. It is eaten by local people in the northwest Himalaya, not only by local villagers but also the Nepali and Tibetan people residing in the lower hills of the Northwestern Himalaya. This species appears to be overexploited in some regions but occurs abundantly in other areas. In general, the former is the case in regions where it is regarded as one of the best edible mushrooms. In these regions, it is found in lower numbers and in scattered localities throughout the forests.

Identification clues: Local villagers identify this fungus in field on the basis of the ovoid structure of the primordial (button) stage, the scarlet red to orange color, and the medium to large fruit body with a thick, saccate volva (cup) at base of the stipe.

Specimens examined: Uttarakhand-KCS 167, 10 July 2000; KCS 173, 15 July 2000 (Pauri, Khirsu, elevation 2200 m); KCS 339, 30 July 2001 (Chobattakhal, elevation 2200 m); KCS 456, 29 July 2002 (Rudraprayag, Chopta, elevation 2500 m); KCS 614, 14 August 2004 (Pauri, Adwani, elevation 2300 m); KCS 1035, 15 July 2007; KCS 1041, 15 July 2007 (Rudraprayag, Jakholi, elevation 2300 m); KCS 1135, 15 Aug. 2007 (Pauri, Kanda, elevation 650 m); KCS 1189, 29 June 2008; KCS 1254, 30 July 2009; KCS 1393, 16 July 2010; KCS 1397, 17 July 2010 (Dehradun, Tapovan, elevation 670 m); KCS 1476, 7 Aug. 2010 (Phedkhal, elevation $2300 \mathrm{~m}$ ). Himachal Pradesh-KCS 1051, 18 July 2007 (Shimla, elevation 2400 m); KCS 1207, 1 Aug. 2008 (Solan, elevation $2000 \mathrm{~m}$ ).

Amanita chepangiana Tulloss \& Bhandary, Mycotaxon 43: 25 (1992)

Figs. 2E, F

Description: Fruit body medium to very large, cap 10-26 cm wide, hemispherical to convex, plane with age, white to cream white, sometimes pale lemon yellow in the middle, dry, but glutinous when wet, glabrous, margin tuberculate-striate, up to $3 \mathrm{~cm}$ thick towards the middle. Gills free, 


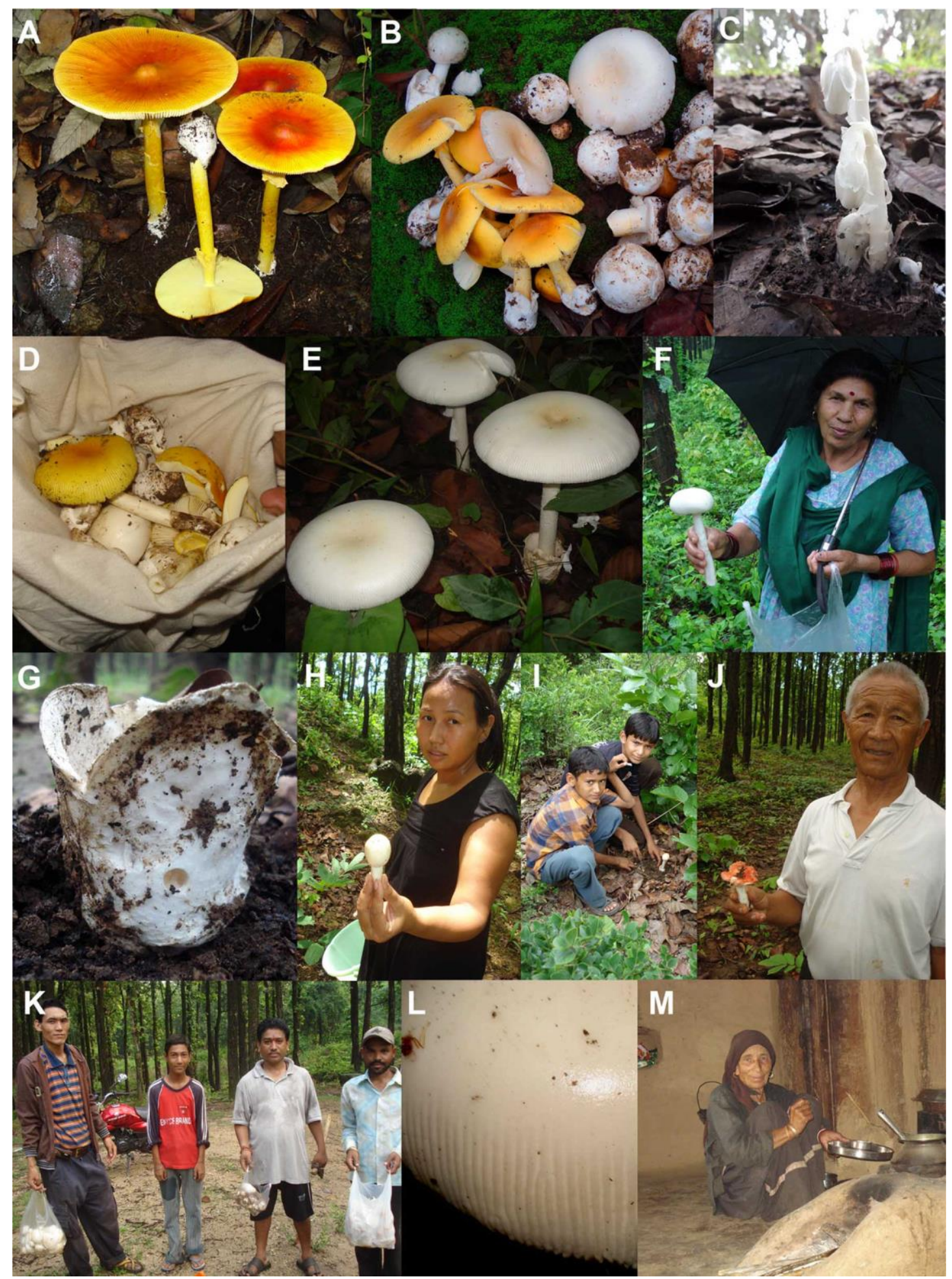

Figures 2A-M - A Amanita hemibapha. B \& D A. hemibapha and A. chepangiana as collected by local people. C Monotropa unifora (Indian pipe) growing naturally in an oak-dominated forest. E A. chepangiana in a forest. F Older woman collecting A. chepangiana from the Ladpur forest near Dehradun. G Large cup-like volva of A. chepangiana. H Tibetan woman collecting A. chepangiana in Dehradun. I Local boys engaged in collecting A. chepangiana in the Kanda forest near Pauri. $\mathbf{J}$ Tibetan man collectiong Russula lepida in Dehradun. K Local people collecting A. hemibapha and A. chepangian in the egg stage. L Striate cap margin of A. chepangiana, a diagnostic feature used to distinguish it from similar species. M Older woman ready to prepare Macrolepiota procera in a "chani" - a place in the high hills where local people live with their cattle during the rainy season. (All photographs by K. C. Semwal.) 
of various lengths, up to $2.3 \mathrm{~cm}$ broad, truncate. Stipe $15-24$ x 1.5-3 cm, white, with whitish appressed, zigzag arranged fibrils, these soon disappearing, annulus superior, consistency thin when compared with A. hemibapha. Volva thick, saccate, often with limbs, prominent, up to $8 \mathrm{~cm}$ long and $6 \mathrm{~cm}$ wide, flesh soft, white to pale yellow. Odor pleasant.

Habitat: Terrestrial, very common at elevations from 600 to $2200 \mathrm{~m}$ in forests dominated by Shorea robusta and Tectona grandis and also extending upwards to oak-dominated areas. This species has not yet been recorded in coniferous forests and thus has a distribution restricted to the lower and middle hills in the Northwestern Himalaya. Amanita chepangiana is a fairly edible mushroom that is a member of a group of deadly poisonous white species of Amanita. Other white species include $A$. verna and A. virosa. Amanita verna is apparently rather similar morphologically to $A$. chepangiana, but the latter can be clearly distinguished on the basis of the deep tuberculatestriate cap margin (Fig 2L) and terete stipe, which tapers upwards, and the thick, very large, saccate, cup-like volva at the base of the stipe (Fig. 2G ). In A. verna, the cap margin is smooth or non-striate cap and the stipe base is bulb-like, spherical, relatively wide, and covered with a membranous volva. The volva is distinctly membranous, limbate (i.e., has a distinct edge) instead of saccate, with a free limb. However, the Asian forms traditionally referred to A. verna have been renamed as A. exitialis Zhu L. Yang \& T.H. Li (Yang et al. 2001), A. oberwinklerana Zhu L. Yang \& Yoshim. Doi (1999) and A. subjunquillea var. alba Zhu L. Yang (1997). Among these, A. exitialis and A. subjunquillea var. alba produce a yellow color in response to an application of dilute potassium hydroxide to their tissue, whereas $A$. oberwinkelerana does not produce any such color change and thus is similar to A. virosa in this respect. This species is eaten by the local people in the Uttarakhand Himalaya, not only by the local villagers but even the Nepali people and Tibetan refugees residing in the lower hills in Uttarakhand, particularly the Dehradun Valley. In the Uttarakhand Himalaya, A. chepangiana is found only in forests in the lower Himalayan range dominated by Shorea robusta and Tectona grandis and in middle Himalayan range in broadleaf forests dominated by oak. It has not yet been observed from the coniferous forests that occur in the present study area. In Nepal and Thailand this species has been observed only in the dipterocarpous forests (Sanmee et al. 2008). The circumscription of this species provided herein is first published record from the Northwestern Himalaya and from India.

Identification clues: Local people recognize this mushroom morphologically on the basis of its white, large egg-shaped form in the primordial stage and the fairly large white, umbrella shape of the fruit body, which has a striate margin. They collect it early in the morning, thinking that it is fresh at this time of the day. Local people along with Nepali and Tibetan residents engage in the collection of this white mushroom (Figs. 2H, I, J, K).

Specimens examined: Uttarakhand-KCS 1042, 15 July 2007 (Rudraprayag, Jakholi, elevation 2300 m); KCS 1114; KCS 1132; KCS 1139, 15 Aug. 2007 (Pauri, Kanda, elevation 650 m); KCS 1251; KCS 1252, 30 July 2009; KCS 1389, 15 July 2010; KCS 1400, 17 July 2010 (Dehradun, elevation $670 \mathrm{~m}$ ).

Amanita vaginata (Bull.) Lam. sensu lato, Encycl. Méth. Bot. (Paris) 1(1): 109. 1783 [“1784”]

Common name: Grisette

Fig. 3A

Description: Fruit body small to medium, cap 6-8 $\mathrm{cm}$ wide, convex to plano-convex, plane with age, slightly umbonate, grayish brown to brown over the disc, becoming light grayish brown to brownish grey outwards, with a strongly tuberculate-striate margin, surface dry, shiny, but viscid when wet. Gills free, whitish. Stipe 5-16 x 1-2.3 cm, with whitish to grayish white appressed, zigzag arranged fibrils, exannulate. Volva saccate, membranous with 2-3 lobes, 2-4.5 cm long.

Habitat: Terrestrial, occurring under a wide range of different tree species. The distribution of this species in the Northwestern Himalaya extends from coniferous, broadleaf to mixed forests, 




Figures 3A-L - A Amanita vaginata growing in a pine forest. B Agaricus compestris growing in a grassland. C A. compestris forming a "fairy ring." D Cantharellus cibarius in a forest habitat. $\mathbf{E} C$. cibarius ready to be prepared for food in the house of a villager. F $C$. minor growing among leaf litter. G Macrolepiota procera collected by a boy in the Nagtibba forest. $\mathbf{H}$ The peculier mace-like shape of $M$. procera I Expanded cap with patches of squamules, an important feature for field identification by the local people. J Pleurotus cornucopie growing on the stem of Euphorbia ("sulla"). K Termitomyces microcarpus growing near an ant mound in a Shorea robusta forest near Dehradun. L T. eurrhizus growing in the Kanda forest near Pauri. (All photographs by K.C. Semwal). 
and it can be found from the lower hills to the middle hills, and even the high hills as well. However, it is consumed in middle Himalaya only in Garhwal region. The tree component of the canopy in the forests in which it occurs includes Pinus roxburghii, P. wallichiana, Abies pindrow, Cedrus deodara, Cupressus torulosa, Quercus leucotrichophora, Q. semecarpipholia, Myrica esculenta, Rhododendron arboreum, Cinnamomum tamala, Betula utilis and Lyonia ovalifolia.

Identification clues: Local people identify this mushroom on the basis of the mouse gray color and white stipe. Although there appears to be no specific character to identify this edible mushroom in the forest by the villagers, when they were asked about what they use as an identifying feature, they replied in a self-assured manner. Upon being asked again, they replied that this is the experience of our elders passed along from generation to generation. However, they did mention the habitat in which the particular species is found year after year. This type of response was received for every wild mushrooms used for edible purposes in the general study area, even the people from Nepal or Tibet who collect these wild mushrooms.

Specimens examined: Uttarakhand-KCS 145, 15 Sept. 1999; KCS 154, 30 June 2000 (Pauri, Ransi, elevation 2100 m); KCS 280, 7 July 2001 (Pauri, Hanuman Mandir Forest, elevation 2000 m); KCS 286, 8 July 2001 (Pauri, Kanskhet, elevation 1800 m); KCS 1190, 26 June 2008 (Dehradun, elevation 670 m); KCS 1427, 1 Aug. 2010 (Dehradun, elevation 670 m).

Agaricus campestris L. [as “campresteri”], Species Plantarum 2: 1173 (1753)

Fig. 3B

Common name: Meadow mushroom

Description: Fruit body small to medium; cap 3.5-7 cm wide, convex, plano-covex with age, sometimes with slightly depressed center, white to faded brownish; appressed fibrilose, grayish brown over disc, becoming light grayish brown outwards; margin smooth. Gills free, pinkish at first, becoming chocolate-brown with maturity. Stipe $3-5.5 \times 0.8-1.5 \mathrm{~cm}$, terete, white to grayish white, smooth to slightly fibrillose; stipe and flesh turned pinkish brown on bruising, annulus superior, thin, disappear soon. Odor pleasant and like that of fennel.

Habitat: Terrestrial, in meadows where it occurs among grasses, sometimes found at forest edges, occurring during the rainy season from June to October, generally most common at lower elevations, often forming fairy rings (Fig. 3C).

Identification clues: This species commonly occurs in grasslands and produces a small, white fruit body, with a superior annulus, pinkish brown gills and odor like that of fennel. Local people identify this mushroom on the basis of its size and odor.

Specimens examined: Uttarakhand - KCS 1004, 12 July 2007; KCS 1258, Aug. 2009 (Dehradun, elevation 670 m, among grass). Himachal Pradesh-KCS 1161, Sept. 2007 (Solan, elevation $1950 \mathrm{~m}$, near the train track).

Cantharellus cibarius Fr., Syst. Mycol. (Lundae) 1: 318 (1821)

Fig. 3D

Common name: Chanterelle

Description: Fruit body medium to large, cap 3.5-9 cm wide, cap shallowly convex, then plane, disc shallowly depressed, yellow, lemon yellow to deep yellow with age, moist, glabrous to minutely tomentose, margin split, enrolled, incurved, non-striate. Hymenium without true gills, reduced to ridges, these extending down stipe, subdistant, forked, sometimes intervened at the margin, with thick edges, concolorous with the cap. Stipe $5-10 \times 0.8-2.5 \mathrm{~cm}$, concolorous with the cap, lighter downwards, terete or tapering downwards, compressed. Odor pleasant, like that of apricot.

Habitat: Terrestrial, fruit body caespitose to solitary, occurring in coniferous, mixed and broadleaf forests but primarily associated with Cedrus, Pinus, Quercus, Rhododendron and Myrica in the general study area. It is found mainly at higher elevations, usually at elevations from 1500 to $2400 \mathrm{~m}$. Not yet recorded from lower elevations in the Garhwal Himalaya, and this is first published record of the species from anywhere in the Garhwal Himalaya.

Identification clues: In the Northwestern Himalaya, the local people we interviewed were found aware of the edibility of this species. When it was introduced to the local people, they 
described their identification clues as the lemon yellow color and apricot odor. Local people started to cook it with traditional method of making curry (Fig. 3E).

Specimens examined: Uttarakhand - KCS 509, 3 Sept. 2001 (Pauri, Adwani, elevation 1950 m); KCS 1276, 26 Aug. 2009; KCS 1278, 26 Aug. 2009; KCS 1290, 27 Aug. 2009; KCS 1293, 27 Aug. 2009; KCS 1298, 27. Aug. 2009 (Champawat, Mayawati, elevation 1950 m); KCS 1313, 28 Aug. 2009 (Champawat, Abott Mountain, elevation 2000 m); KCS 1736, 18 Aug. 2013; Aug 26, 2013 (Pauri, Khirsu, elevation 1800 m). Himachal Pradesh-KCS 1060, 5 Aug. 2007 (Churdhar, Rajgarh, elevation 1555 m); KCS 1084, 9 July 2008 (Solan, Karol, elevation 2200 m).

Cantharellus minor Peck, Ann. Rep. Reg. N. Y. St. Mus. 23: 122 (1872)

Fig. 3F

Common name: Chanterelle

Description: Fruit body small to very small, cap $0.5-3 \mathrm{~cm}$ wide, convex with recurved or enrolled margin, then flat with a depressed center, appearing funnel-shaped, thin, waxy, yellow to pale yellow, smooth, margin wavy. Hymenium with thick, bifurcate, broken, decurrent, distant to subdistant, yellowish gills-like structures. Stipe 1.8-4.5 x 0.3-0.8 cm, concolorous with the cap, smooth, terete. Odor pleasant, like that of apricot.

Habitat: Terrestrial, solitary to connate, growing in oak, mixed and coniferous forests, in mossy soil, among decomposing leaf litter. The distribution of this species is similar to that of $C$. cibarius at higher elevations. This is first published record of the species from Garhwal Hiamlaya.

Identification clues: This species was not well known to the local people but was introduced to them in a manner similar to that noted for $C$. cibarius.

Specimens examined: Uttarakhand - KCS 335, 11 Aug. 2000 (Pauri, Khirsu, elevation 1800 m); KCS 445, 28 July 2001 (Pauri, Adwani, elevation 1950 m); KCS 1289, 27 Aug. 2009 (Champawat, Mayawati, elevation 1950 m); KCS 1732, 5 Sept. 2013 (Pauri, Phedhkhal, elevation $1900 \mathrm{~m})$.

Hericium erinaceus (Bull.) Pers., Comm. Fung. Clav. (Lipsiae): 27 (1797)

Common name: Lion's mane or hedgehog mushroom

Description: Fruit body medium to large, up to $15 \mathrm{~cm}$ across, whitish, becoming dirty brownish yellow with age, fleshy, with long spines, these projecting downwards, $1-4.5 \mathrm{~cm}$ long, pointed. Stipe short, thick, whitish, with a lateral position.

Habitat: Occurring in cracks in living but decaying broadleaf trees, most common on Quercus leucotrichophora. This is first published record of the species from the Garhwal Himalaya.

Identification clues: This species, locally known as bakercheun, appears similar in appearance to a goat's beard. Local people identify this species on the basis of its habitat, since it is found only on the trunks of oaks and Rhododendron trees and has such a distinct appearance. It is commonly consumed by villagers in the general study area.

Specimens examined: Uttarakhand-KCS 509, 26 Aug. 2002 (Pauri, Adwani, elevation 1950 m). Himachal Pradesh-KCS 1162, 23 Sept, 2007 (Shimla, Jakhu Hills, elevation 2400 m).

Macrolepiota procera (Scop.) Singer, Pap. Mich. Acad. Sci. 32: 141 (1948) [‘1946’] Figs. 3G, I Common Name: Parasol mushroom

Description: Fruit body medium to large, cap 7-14 $\mathrm{cm}$ wide, hemispherical, to convex to plano-convex with age, with flat umbo in the middle, with an overall shape that is always peculiar due to the long stipe and broad spherical shape of the unopened cap of the fruit body, when it looks somewhat like a mace (Fig. 2H), white, often covered with light brown to brownish small squamules, split and scattered due to the expansion of fruit body, disc smooth, brownish. Gills free to remote, of various length, broad, densely crowded, thin, white. Stipe cylindrical with broadened base, 15.5-24 x 1.0-2 cm, covered with whitish to brownish squamules, hollow with age, annulus superior, whitish, with a brownish dorsal side, movable on the stipe but soon disappearing due to handling, cottony. 
Habitat: Terrestrial, very common, found at forest edges, in grasslands, sometimes among heather, occurring in the lower hills to middle hills, most often just outside a Pinus roxburghii forest canopy among grasses. This mushroom also is associated with species of Eucalyptus. Macrolepiota procera is collected for food throughout the Northwestern Himalaya from Garhwal to Himachal Pradesh. This is first published record of the species from the Garhwal Himalaya.

Identification clues: Villagers identify this mushroom on the basis of the white cap with wine brownish patchy, scattered scales, the moveable ring on the stipe and the somewhat smooth stipe with a slightly swollen base (Fig. 3G). The flesh is white, turning pinkish brown on handling. This mushroom was consumed by first author soon after collection, when it was prepared by the grandmother of the local boy who assisted in forest forays and provided information on the uses of wild fungi in the general study area (Fig. 2M). These people collect wild mushroom to eat during their stay in chaani, a place in the high hills where villagers live with their cattle during the monsoon season when grazing their animals in grassland.

Collection examined: Uttarakhand-KCS 473, 16 Aug. 2002 (Pauri, Teka, elevation 2000 m); KCS 1223, 17 July 2007; KCS 1237, 21 July 2009; KCS 1424, 28 July 2010 (Dehradun, elevation 650 m). Himachal Pradesh: KCS 800, Aug. 2006 (Solan, Rajgarh, elevation 1555 m).

Lactarius camphoratus (Bull.) Fr., Epicr. Syst. Mycol. (Upsaliae): 346 (1838)

Common name: Milky mushroom

Description: Fruit body small to medium, cap 1.5-5.5 $\mathrm{cm}$ wide, plano-convex to plane with age, with a prominent, small acute umbo in the middle, reddish brown, surface viscid when moist, margin often furrowed. Gills adnate to subdecurrent, orange white to pale orange, finally brownish orange. Stipe 1.4-6 x 0.4-1.4 cm, cylindrical, slender, concolorous with the cap. Latex milk-white or whey-like, scanty, unchanging upon exposure to air, taste mild. Odor fragrant.

Habitat: Terrestrial, solitary to scattered, often on moist banks or in damp places, usually under Quercus leucotrichophora, Rhododendron arboretum, Cedrus deodara and Pinus wallichiana.

Identification clues: Only few local people were found to be aware of the edibility of this mushroom. They identify it on the basis of the white latex produced when a fruit body is cut. The color of the latex does not change upon exposure to air as is the case for some other species of Lactarius.

Specimens examined: Uttarakhand-KCS 391, 2 Sept. 2000 (Pauri, Ransi, elevation 2100 m); KCS 1238, 21 July 2009 (Dehradun, Chaukrauta, elevation 2300 m).

Lactarius azonites (Bull.) Fr., Epicr. Syst. Mycol. (Upsaliae): 348 (1838)

Common name: Milky mushroom

Description: Fruit body small to medium; cap 3-6.5 cm wide, convex to plano-convex, applanate with age, center often depressed, grayish brown to dark brown, smooth, glabrous to thin velvety. Gills adnate to subdecurrent, close, forked, whitish to yellowish white in age, reddening on bruising. Stipe $2.5-7$ x $0.8-1.3 \mathrm{~cm}$, slightly tapering below, concolorous with the cap to slightly paler, surface pruinose. Latex white, milky, turning the tissue reddish upon bruising, taste acrid. Odor not distinctive.

Habitat: Terrestrial, solitary to scattered, found only with broadleaf trees, especially such species as Quercus leucotrichophora, Rhododendron arboretum and Myrica esculenta.

Identification clues: The use of this species for food is restricted to only the Garhwal Himalaya. The local people identify this Lactarius on the basis of the darkening of the fruit body upon bruising but do not consider this as highly edible as Lactarius camphoratus.

Specimens examined: Uttarakhand - KCS 539, 12 Sept. 2002 (Pauri, Kuinkaleshwer, elevation 2000 m); KCS 1051, 15 July 2007 (Rudraprayag, Jakholi, elevation 2300 m).

Pleurotus cornucopiae (Paulet) Rolland, Acta Prytogeogr. Suec.: Pl. 44, Fig. 36 (1910) Fig. 3J Common name: Oyster mushroom 
Description: Fruit body small, cap 3-5 cm wide, fan-shaped, applanate, center often depressed, whitish with light pinkish hue, smooth, glabrous to thin velvety in the center. Gills decurrent, extending down the stipe, close, whitish. Stipe lateral, $2.5-4$ x 0.6-1 cm, slightly tapering below, concolorous with the cap.

Habitat: Lignicolous, occurring on species of Eurporbia and the dead wood of an unidentified tree in the lower hills in the Garhwal Himalaya. The local people collect and eat this mushroom, but this is first published record of the species from the Garhwal Hiamlaya.

Identification clues: This species is commonly known as sulla chewun because it is generally found on the wood of Eurphorbia, and the latter is locally called sulla. The local people identify this mushroom on the basis of its fan-shaped structure, the association with sulla, and the smooth whitish cap with decurrent, thin gills.

Specimens examined: Uttarakhand-KCS 1145, 16 Aug. 2007 (Pauri, Kanda, elevation 650 m). Himachal Pradesh-KCS 1173, 23 Sept. 2007 (Solan, elevation 2000 m).

Termitomyces microcarpus (Berk. \& Broome) R. Heim, Mem. Acad. Roy. Sci. Inst. France 64: 72 (1941)

Fig. 3K

Description: Fruit body very small, 1-3 cm wide, more campanulate than applanate when fully expended, often with a small umbo, grayish brown, umbo darker, radial streaks towards the margin, the margin often split. Gills free, thin. Stipe 3.5-6.5 x 0.2-0.4 cm, cylindrical, thin, fleshy, cream white, smooth, lacking a pseudorrhiza and exannulate.

Habitat: Terrestrial, very common in deciduous forests with Shorea robusta and Tectona grandis present in the lower Shiwalik Hills in the Garhwal Himalaya. Gregarious to scattered near termite mounds, occurring in troops of fruit bodies that sometimes number in the hundreds. This is the first published record of the species from the Garhwal Hiamlaya.

Identification clues: It is easy to recognize due to the very small size of the fruit body, the habitat (i.e., growing near termite mounds) and the fact that it occurs in large groups.

Specimens examined: Uttarakhand-KCS 1138, 15 Aug. 2007 (Pauri, Kanda, elevation 650 m); KCS 1423, 27 July 2010; KCS 1512, 29 Aug. 2010 (Dehradun, elevation 650 m).

Termitomyces eurrhizus (Berk.) R. Heim, Arch. Mu. Hist. Nat. Paris, Ser. 6, 18: 140 (1942)

Fig. 3L

Description: Fruit body medium to large, cap 4.5-8.5 $\mathrm{cm}$ wide, cap conico-campanulate, then applanate with large a conic papilla at the center of the disc, light brownish to grayish brown, surface tuberculate to bumpy, margin split, non-striate. Gills free, white, crowded, lamellulae of various length, edges serrate. Stipe (epigeal) 10-14.5 x 0.7-1.6 cm, cylindrical, clavate downwards, grayish white to dirty white, lightly fibrillose at apex, exannulate, pseudorrhiza up to $6 \mathrm{~cm}$ long.

Habitat: Terrestrial, caespitose, solitary, growing in soil on ant mounds in broadleaf forests, mainly those containin Shorea robusta and Pinus roxburghii in the Shiwalik Range. This is first published record of this mushroom from the Garhwal Hiamlaya.

Identification clues: The local villagers identify this mushroom specifically on the basis of its habitat, the grayish brown cap, conic umbo and prominent pseudorhiza. They refer to the pesudorhiza as poonch, meaning tail. $650 \mathrm{~m})$.

Specimens examined: Uttarakhand - KCS 1131, 15 Aug. 2007 (Pauri, Kanda, elevation

Termitomyces heimii Natarajan, Mycologia 71(4): 853 (1979)

Fig. 4A

Description: Fruit body medium to large, cap $4.7-9.5 \mathrm{~cm}$ wide, cap plano-convex with a distinct conic umbo at the center of the disc, white to bone white, umbo darker as grayish brown, surface rugose to rugulose (wrinkled), or appeared as irregular striate. Gills free to adnexed, crowded, white at first, later on pinkish to pale pinkish, edges serrulate, lamellulae of 6-7 ranks. Stipe (epigeal) 6-9.5 x 0.6-1.5 cm, cylindrical, tapering downwards, white, below annulus covered 


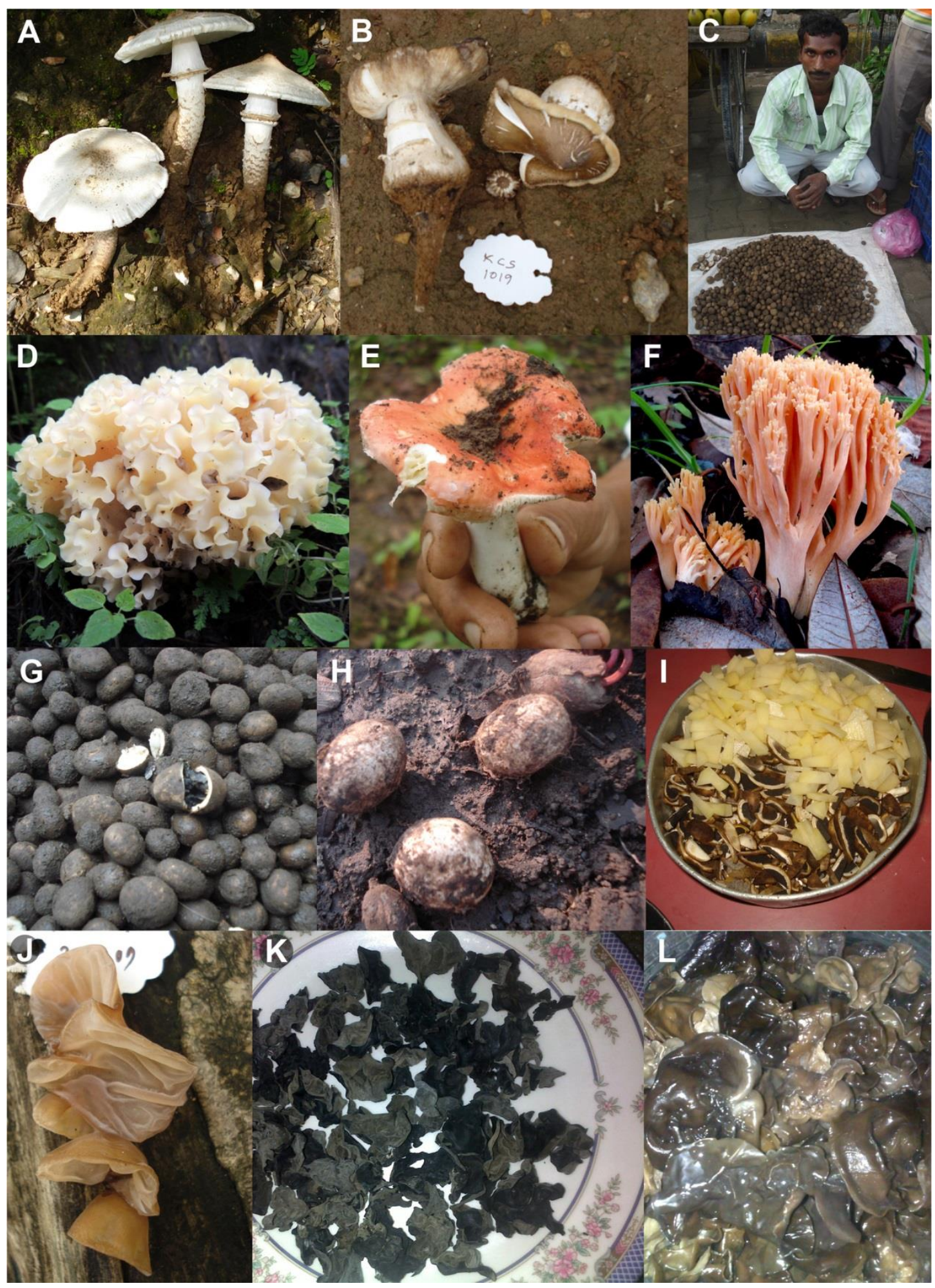

Figures 3A-L - A Termitomyces heimii in nature. B Termitomyces sp. growing near the edge of an oak-dominated forest near Jakholi. C A local vendor selling Astraeus hygrometricus ("phutphut") in a local market in Dehradun. D Sparassis crispa growing near the base of a Cedrus deodara tree in the Nagdev forest near Pauri. E Russula lepida collected by a Tibetan resident in a Shorea robusta forest in Dehradun. F Ramaria botrytis in a mixed forest of Teka near Pauri. G $A$. hygrometricus in a local market. H A. hygrometricus growing in a forest near Dehradun. I $A$. hygrometricus ready to cook along with potatoes. J Auricularia auricula-judae growing on the living stem of an unknown tree in Dehradun. K Dried A. polytricha collected by Tibetan residents. L A. polytricha revived in water to be cooked along with onions and potatoes by Tibetan resident. (All photographs by K.C. Semwal.) 
with finely ornamented fibrillose to floccose fibrils, brownish, annulus superior, appear as double due to uplift edges on both side, off white at ventral side, white in dorsal side with striate appearance due to gills attachment during primordial stage attachment, pseudorrhiza 6-10 x 0.3-0.7 cm long.

Habitat: Terrestrial, solitary, growing in soil on ant mounds, often beneath the canopy of Shorea robusta and Pinus roxburghii in the Shiwalik Range. The habitat is similar to that of $T$. eurrhizus. This is first published record of the species from Garhwal Hiamlaya.

Identification clues: The same as indicated for other species of Termitomyces.

Specimen Examined: Uttarakhand - KCS 1140, 15 Aug. 2007 (Pauri, Kanda, elevation $650 \mathrm{~m})$.

Termitomyces sp.

Fig. 4B

Description: Fruit body small to medium, cap 4-5.5 $\mathrm{cm}$ wide, cap applanate with distinct conic broad umbo at disc, brown, with darker disc, light brown towards margin, surface split due to maturation of fruit body; margin smooth, uplifted, recurved, irregular, split. Gills free to adnate, densely crowded, whitish, becoming dirty white. Stipe (epigeal) 5-5.5 x 2-2.5 cm, tapering upwards, white, broadly clavate or expanded towards down, up to $3 \mathrm{~cm}$ broad, pseudorrhiza tapering downwards, 4 x $5 \mathrm{~cm}$ long.

Habitat: Terrestrial, solitary, scattered, growing in soil near the edge of an oak-mixed forest at higher elevations, near an ant mound.

Identification clues: The same as for other species of Termitomyces.

Specimen examined: Uttarakhand - KCS 1019, 15 July 2007 (Rudrapryag, Jakholi, elevation $2300 \mathrm{~m})$.

Sparassis crispa (Wulfen) Fr., Syst. Mycol. (Lundae) 1: 1821

Fig. 4D

Common name: Cauliflower fungus

Description: Fruit body medium to large, $13-28 \mathrm{~cm}$ in diam., made up of curly and folded fronds, giving appearance of lettuce leaf or cauliflower, cream to cream-yellow to egg yellow with age. Stipe thick, stout, short and yellowish white.

Habitat: This mushroom is easily identified from its shape and quickly attracts mushroom hunters. It generally occurs in coniferous forests on the ground at the base of Cedrus deodara. This is first published record of the species from the Garhwal Hiamlaya.

Identification clues: During our surveys in the forests, discussions with the local residents revealed many interesting bits of information. The local people identify many species of mushrooms on the basis of specific features found in a particular species and not necessarily features that are shared with other species. For example, this species is identified from the curly-flat folded, flower-like, cream-colored elongated branches on a short stalk, with the fruit body generally occurring at the base of a conifer.

Specimens examined: Uttarakhand-KCS 1215, 5 July 2009, KCS 1216, 5 July 2009 (Tehri, Dhanolti, elevation 2200 m); KCS 1660, 28 July 2013 (Pauri, Nagdev-Jhandidhar, elevation $2100 \mathrm{~m})$.

Ramaria botrytis (Pers.) Ricken, Vadem. Pilzfr.: 253 (1918)

Fig. 4F

Common name: Coral fungus

Description: Fruit body robust, branched, up to $11 \mathrm{x} 4 \mathrm{~cm}$ when fully expanded, bright pinkish orange, terminal branches fading to pale yellowish. Stipe short, up to $6 \times 2.5 \mathrm{~cm}$, thick with many branches, branches repeatedly dichotomous, rhizomorph whitish.

Habitat: Terrestrial, growing in mixed forests containing oak, Myrica and Pinus roxburghii. This is first published record of the species from the Garhwal Hiamlaya.

Identification clues: This mushroom is easy to recognize due to its finger like projections and overall shape. However, local people tend to be conservative in their selection of species of 
Ramaria to eat. Only few people identify and eat this species with confidence in both Uttarakhand and Himachal Pradesh. Locally, they refer to the mushroom as ungli-cheun in Uttarakhand and siun in Himachal Pradesh.

Specimens examined: Uttarakhand-KCS 1519, 16 Aug. 2010 (Pauri, Teka, elevation 2000 m). Himachal Pradesh-KCS 1173, 23 Sept. 2007 (Shimla, Jakhu Hill, elevation 2400 m).

Russula lepida Fr., Anteckn. Sver. Ätl. Svamp.: 50 (1836)

Fig. 4E

Description: Fruit body small, cap $4.5-6 \mathrm{~cm}$ wide, convex to applanate, slightly depressed in the middle, pinkish red, discolor or light in color with age, margin incurved with age. Gills adnate, narrow, whitish to creamish, sub-distant, fragile as fruit body. Stipe 5.5-7 x $0.7 \mathrm{~cm}$, cylindrical, attenuate at the base, whitish.

Habitat: Terrestrial, solitary, scattered, growing among leaf litter in humicolous soil in Shorea robusta forests. Local people and Tibetan residents collect and eat this mushroom in the lower Shiwalik Hills of Uttarakhand.

Specimen examined: Uttarakhand-KCS 1328, 6 Sept. 2009 (Dehradun, Tapovan, elevation $650 \mathrm{~m}$ ).

Astraeus hygrometricus (Pers.) Morgan, J. Cincinnati Soc. Nat. Hist. 12: 20 (1889)

Fig. $3 \mathrm{H}$

Common name: Earthstar

Description: Fruit body small, globose to subglobose, $2.5-4.2 \mathrm{~cm}$ diam., with the mature fruit body having the appearance of an earth star when the outer peridium ruptures to form triangular-shaped lobes that radiate outward from the apex of globose fruit body, exposing the inner peridium with a conspicuous ostiole.

Habitat: Terrestrial, growing on soil, always associated with broadleaf forests in the lower Shiwalik Hills in the Garhwal Himalaya. The main tree components of these forests include Shorea robusta and Tectona grandis. This species is very popular in the city of Dehradun because of its taste. During rainy season locals collect this mushroom from the forests and sell it in open local markets, with prices ranging from $40-60 \mathrm{Rs} / \mathrm{Kg}$ (Figs. 4C, G). The recipe used for this mushroom is to prepare it along with fried onions and potatoes (Fig. 3I). This is first published record of the species from the Northwestern Himalaya.

Identification clues: According to local collectors, this species is not easy to find in the forest since it occurs at or below the surface of the soil. They need keen eyes to search it on forest floor. They collect it with the help of their friends working in groups (Fig. 4H).

Specimens examined: Uttarakhand-KCS 1259, 3 Aug. 2009; KCS 1327, 6 Sept. 2009 (Dehradun, open local market in Ladpur, elevation 650 m); KCS 1390, 15 July 2010 (Dehradun, near the Dolphin Institute, elevation $660 \mathrm{~m}$ ).

Auricularia auricula-judae (Bull.) Quél., Enchir. Fung. (Paris): 207 (1886)

Fig. 4J

Common names: Tree-ear, Jew's ear, wood ear and jelly ear

Description: Fruit body small, irregularly fan-shaped, $2.0-6.5 \mathrm{~cm}$ wide, sessile or sometimes attached to the substrate by a short stalk, inverted cup-like, upper surface soft and fluffy, light brown to wine brown, lower surface smooth to hairy in the middle, wrinkled, pale brownish, gelatinous.

Habitat: Lignicolous, occurring on living and dead wood, solitary to gregarious, sometimes caespitose. Generally found during the monsoon season from June to mid-October. This species has been recorded from the wood of Grievillea robusta (silver oak), Delonix regia (locally known as gulmohar), Bauhinia malabarica (locally known as kachnaar) and Quercus leucotrichophora in the Garhwal Himalaya. It is consumed only by the Tibetan refugees, who refer to it as muro. These people consume it fresh and dried as well. Dried fruiting bodies are revived with water and then fried along with onions. The local people are not aware of the edible quality of this mushroom, and this is first published record of the species from the Garhwal Himalaya.

Identification clues: Fruit body ear-like, brown, transparent, with a viscid texture. 
Specimens examined: Uttarakhand - KCS 1241, 29 July 2009 (Dehradun, Vasant Vihar, elevation 650 m); KCS 1249, 29 July 2009 (Dehradun, Gari Cant, elevation 650 m).

Auricularia polytricha (Mont.) Sacc., Atti Inst. Veneto Sci. Lett., ed. Arti, Sér. 6 3: 722 (1885)

Fig. 4K

Description: Fruit body small, fan-shaped, $3.5-8 \mathrm{~cm}$ wide, dark brown to brown, upper surface glutinous, smooth, dorsal side hairy, grayish black.

Habitat: Lignicolous, grows on live and dead wood, solitary to gregarious, sometimes caespitose. In general, the habitat is very similar to that of $A$. auricula-judae. This mushroom is consumed in the same manner as A. auricula-judae by the Tibetan people (Figs. 4K, L) but not consumed by the local people. This is first published record of the species from the Garhwal Hiamlaya.

Identification clues: Similar to A. auricula-judae.

Specimen examined: Uttarakhand-KCS 1521, 16 Aug. 2010 (Dehradun, Sahastradhara Road, elevation $650 \mathrm{~m}$ ).

\section{Ascomycetes}

Cordyceps sinensis (Berk.) Sacc., Michelia 1(no. 3): 320 (1878)

Common names: Caterpillar fungus, keeda ghaas, keeda jari or yarshagumba

Description: Fruit body appearing as cylindrical, pipe-like structure with a swollen head. Stomata black, with a broadened apex. Stipe $3.5-4 \mathrm{~cm}$ long, $0.2 \mathrm{~cm}$ wide, apex up to $0.4 \mathrm{~cm}$ wide and $1.5-2.0 \mathrm{~cm}$ long, stipe surface furrowed, smooth.

Habitat: Terrestrial, solitary, generally emerging from the soil in May and July, common during the early rainy season in alpine zones of Rudraprayag. This fungus grows on insect larvae of Hepialus oblifurcus (Arora \& Dhaliwal 1997). It found mostly in association with the dwarf shrub Rhododendron anthopogon (sonpati). The local people assume that it is always found near this tree and use this as a habitat indicator. Local people only collect this mushroom and sell it to local vendors who export it to markets in China and Nepal. The price varies from about 55,000 to 80,000 INRs/kilogram. However, due to the unplanned and furtively overexploitation of Cordyceps sinensis in high elevation areas of the Garhwal Himalaya, the chances of this medicinally important fungi occurring in next rainy season are greatly reduced. There is even the possibility of it going extinct in the region. In the Garhwal Himalaya it has only medicinal value.

Identification clues: Local peoples identify this species on the basis of the thin, small, extending upright from the ground, brown-black fruit body.

Specimens examined: Uttarakhand - KCS 608, 12 June 2003 (Rudryaprayag, Tungnath, elevation $3300 \mathrm{~m})$.

Morchella esculenta (L.) Pers., Syn. Meth. Fung. (Göttingen) 2: 618 (1801)

Fig. 4A

Common name: Sponge mushroom or yellow morel

Description: Fruit body small to medium, apothecia 4.0-6.5 cm long, 3-4.5 cm wide, rounded to ovoid, sometimes elongated to conical, often unicolor, dull yellowish to yellowish brown, outer surface with irregular pits and ridges, ridged yellowish, grayish brown at maturity. Stipe 4.0-6.5 cm long, 1.3-2.5 cm wide, creamish, wrinkled, often granulose, hollow, slightly expanded at the base with an obvious depression.

Habitat: Terrestrial, occurring only in coniferous forests and found in humicolous soil associated with the leaf litter of Cedrus deodara, Cupressus torulosa, Picea smithiana, and Abies pindrow. There has long been a myth about this mushroom in the general study area. People assumed that the fruiting bodies of guchhi (the local name for the morel) appear on the forest floor only after lightning and thunder storms in the early part of the rainy season during March and April. As such, they used to go and collect this mushroom only after lightning had occurred. However, $M$. esculenta has been collected from apple orchards at the Bharsar locality in the Garhwal Himalaya in the month of October (early autumn) by the first author. Local people understand that morels tend to be limited to certain habitats. For example, they collect this mushroom very easily as a 


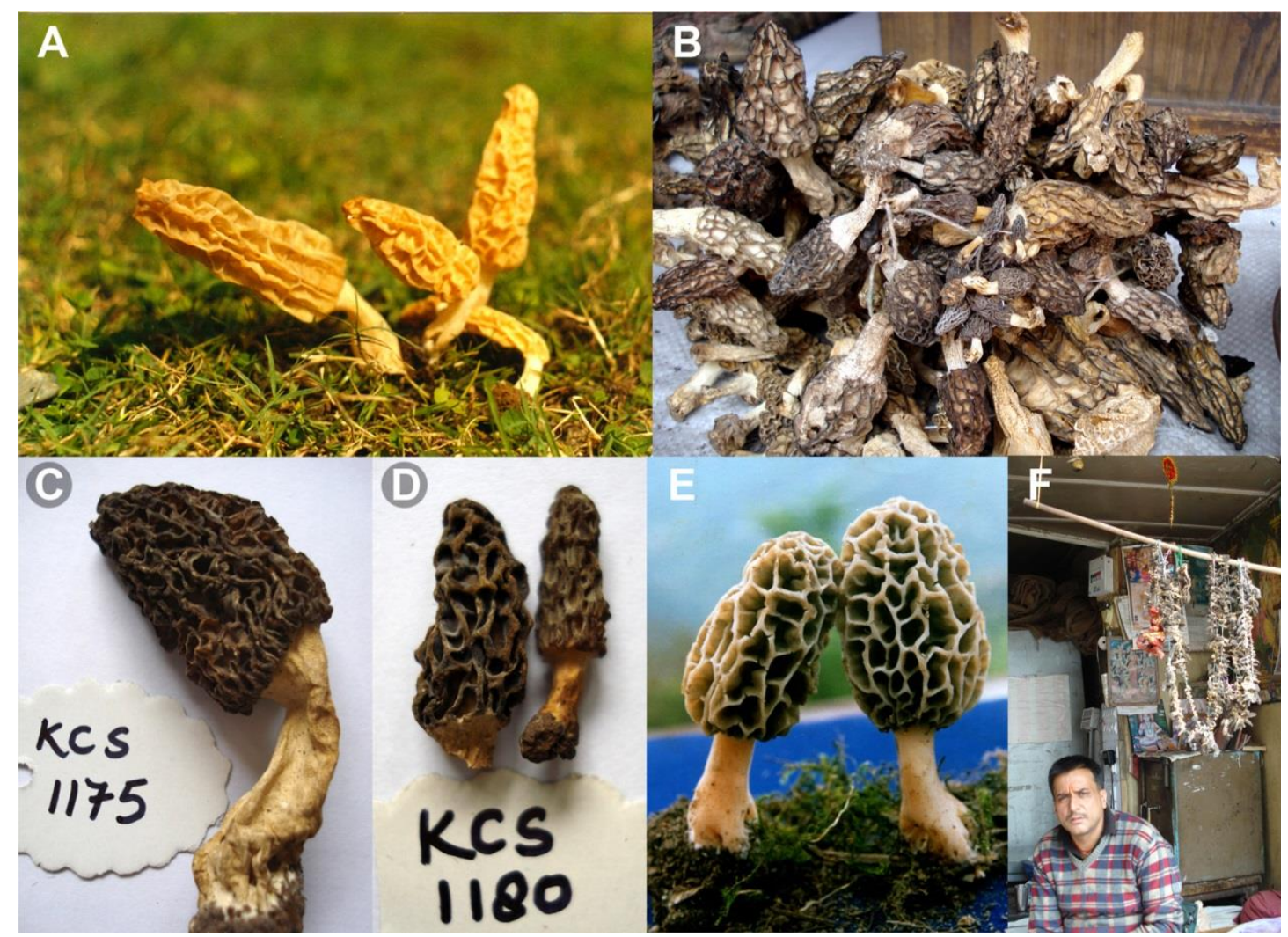

Figures 4A-F - A Yellow morel (M. esculenta) in the field. B Morels being sold in an open market in Shimla C Black morel (M. elata). D M. conica. E Grey morel (M. deliciosa). F Morel vendor in Shimla. (All photographs by K.C. Semwal.)

results of knowing that it can be found near streams, in wet and humid soil along with the leaf litter of Cedrus deodara or other coniferous trees, often with Seleginella also present. A number of morels collected in the Northwestern Himalaya have been assigned to the yellow morels $(M$. crassipes and $M$. spongiola) and black morels (M. elata, M. angusticeps and M. gigas) as reported by Kanwal et al. (2011). However, local people collect this mushroom without knowing the different species involved in guchhi. They consider morels as nutritious as meat due to its taste being somewhat similar to the latter. The morels tentative identified in the present study include what appear to be M. elata (Fig. 5C), M. deliciosa (Fig. 5E) and M. conica (Fig. 5D). Morel fruiting bodies that are dried and brought to the local market are sold at a high price (Figs. 5B, F). Local vendors try to obtain the maximum possible price for this commodity. In the Bhotia tribe found in the high elevations of the Chamoli District of Uttarakhand used to make a decoction of $M$. esculenta by boiling the fruiting bodies in water. The local people in the Kullu District of Himachal Pradesh boil fruiting bodies in milk before they are consumed (Nautiyal et al. 2001). As already noted, the local name for a morel in Uttarakhand is guchhi, but in the Himachali language it is known as chunchuroo.

Identification clues: This mushroom is identified by the local people on the basis of the honeycomb- or network-like fruit body and the usual habitat of the species. Locals are aware of the color differences of the specimens they collect and identify them as yellow morels or black morels.

Specimens examined: Uttarakhand-KCS 251, 15 March. 2000 (as M. esculenta, Pauri, Nagdev, elevation 2100 m); KCS 335, 28 March. 2001 (as M. deliciosa, Pauri, Nagdev-Jhandidhar, elevation 2200 m). Himachal Pradesh-KCS 1175, 2 April 2008 (as M. elata, Shimla in the local market); KCS 1180, 2 April 2008 (as M. conica, Shimla in the local market).

\section{Preparation for Cooking}

The methods used to cook all of these wild edible wild mushrooms were found to be somewhat similar to those used for local vegetables, with a few exceptions. After being collected 
the mushrooms are cleaned with saline water and then fried along with onion, garlic and tomato. Fruit bodies of Astreatus (phutphut) were mixed with potato after being fried with onion, garlic and tomato, whereas a drop of lemon was added to the fruit bodies of Termitomyces during cooking, which is thought to avoid any possibility of the mushroom being poisonous. The fruit bodies of Auricularia spp. are soaked with hot water for 10-20 minutes and then fried with onion and other things.

\section{Introduction of New Edible Species of Mushrooms}

In the hills and valleys of Uttarakhand and Himachal Pradesh are inhabited by a considerable population of Nepali people who are engaged in the cultivation of cash crops such as cabbage, tomato and other crops in those agricultural fields where previously other cereal crops were grown by the local peoples but due to mass escapes of the local young people's for employment, these fields are on lease to Nepali peoples to grow cash crop to raise the economy of the concerned family. With the crop cultivation work, these Nepali people exploit the fungi for their dietary and share their knowledge with the local peoples. They are not only collecting edible wild fungi, they are exploiting Cordyceps and Morchella species from the region. Morchella is highly prized for its delicious, nutritive value and Cordyceps is highly medicinal properties and it plays a great role in the Chinese and Tibetan local remedies. A large number of Tibetan refugees are living in the valleys of Himachal Pradesh and Uttarakhand Himalaya and they are also exploiting the higher fungi for food in their localities. These Nepali peoples and Tibetan refugees introduced new edible species to the local area; previously these were not consumed in the study area.

There is relatively little folklore and very limited data are available relating to the local uses of wild mushroom as food or medicine by the local villagers, the Nepali people and Tibetans in the general study area, despite the fact that people throughout this region have eaten or used them for centuries. The morels, Astraeus and Cordyceps are the only species that have some value respect to providing income to rural people. Beginning with the spring season and continuing until the early rainy season, people collect morels and eat them or dry the fruit bodies to be sold in local market at very low price (Fig. 4C, Figs. 5B, F).

\section{Warranted Actions to Protect the Mycodiversity of the Northwestern Himalaya}

All of the wild edible mushrooms (WEM) described herein have long been used by the local people in the Himalaya, but there are no laws to monitor activities relating to the proper collection of these highly valuable non-timber forest product (NTFP) resources. Laws are available only for collecting strategies associated with Cordyceps sinensis due to its high price and high demand in Chinese-Tibetan traditional medicine. In order to ensure the conservation of species in the wild, the Uttarakhand government has issued guidelines for proper and sustainable collection of keera ghaas in this state. According to these laws, peoples can go to alpine regions only in the months of May and July. A local government organization called the Van Panchyat/Gram Panchyat and established by the state government issues collection authority letters only to local villagers (Singh et al. 2010).

Edible wild mushrooms can be found from lower elevations to higher elevation in the Northwestern Himalaya. At every elevation they are important as food and for trade as well as representing an essential part of forest ecosystems since they form ectomycorrhizal associations with tree roots. Some species are specific to a particular host, but others can form associations with a number of different kinds of trees. For the improvement of forest health, scientists can identify the species of fungi involved and use the mycelium to inoculate seedling trees in a nursery and enhance tree growth in a plantation. There is a need to establish a "mushroom germplasm bank" to conserve this wild natural food and medicine resource, which also can serve as a source of nutraceutical. There is a need to grow live tissues in the laboratory, maintain these tissues in the laboratory, and develop the techniques required to domesticate these mushrooms. 


\section{Acknowledgements}

The authors are thankful to the various groups of local people, Tibetan refugees and Nepali residents for assisting in providing information to the authors; allowing the first author to take photographs in the field and to collect wild mushrooms. Thanks also extended to the local villagers who helped collect wild mushrooms in the forests, responded to the questionnaire, cooperated throughout the entire investigation and especially on field trips. Sincere appreciation to the Head of the Department of Botany, HNB Garhwal University, Srinagar, Uttarakhand for helping in many ways during this study. The final versions of the figures used herein were prepared by Randy Darrah, a former student of the second author.

\section{References}

Adhikary RK, Baruah P, Kalita P, Bordoloi D. 1999 - Edible mushrooms growing in the forests of Arunachal Pradesh. Advances in Horticulture and Forestry 6, 119-123.

Arora D. 1986 - Mushroom Demystified. Ten Speed Press, Berkeley.

Arora AS, Dhaliwal GS. 1997 - The Insect Diversity, Habits and Management. Kalyani Publication, New Delhi.

Barua P, Adhikary RK, Kalita P, Bordoloi D, Gogol A, Singh RS, Ghosh AC. 1998 - Wild edible mushrooms of Meghalaya. Ancient Science of Life 17(3), 1-4.

Bhatt RP, Lakhanpal TN. 1988 - Amanita fulva (Schaeff. ex Pers.)- An edible mushroom new to India. Current Science 57, 1126-1127.

Bhatt RP, Lakhanpal TN. 1989 - A new record of edible Amanita from India. Current Science 58 (11), 627-628.

Boa E. 2004 - Wild edible fungi: a global overview of their use and importance to people. NonWood Forest Products, No. 17, FAO, Forestry Department, Rome, Italy.

Boruah P, Singh, RS. 2001 - Edible fungi of medicinal value from the eastern Himalaya region. International Journal of Medicinal Mushrooms 3, 124.

Boruah P, Adhikary RK, Kalita P, Bordoloi D. 1996 - Some edible fungi growing in the forest of East Khasi Hills (Meghalaya). Advances in Forestry Research in India 14, 214-219.

Christensen M, Larsen HO. 2005 - How can collection of wild edible fungi contribute to livelihoods in rural areas of Nepal? Journal of Forest and Livelihood 4(2), 50-55

Binion DE, Stephenson SL, Roody WC, Burdsall HH, Vasilyeva LN, Miller OK. 2008 Macrofungi Associated with Oaks of Eastern North America. West Virginia University Press, Morgantown.

FAO. 2004 - Non wood forest products, wild edible fungi: A global overview of their use and importance (Boa E, ed.). FAO Publications, Rome.

Giri S, Biswas G, Mandal SC, Acharya K. 2012 - Studies on pharmacognostic profile of three medicinally important wild edible mushrooms. International Journal of Pharm Tech Research 4(4), 1595-1600.

Hardman A, Limbird L, Gilman A. (eds.). 2001 - The Pharmacological Basis of Therapeutics. Tenth edition, McGraw Hill, New York.

Harsh NSK, Rai BK, Ayachi SS. 1993 - Forest fungi and tribal economy - a case study in Baiga tribe of Madhya Pradesh, India. Journal of Tropical Forestry 9, 270-279.

Harsh NSK, Rai BK, Soni VK. 1999 - Some ethnomycological studies from Madhya Pradesh, India. In J. Singh \& K.R. Aneja, eds. From ethnomycology to fungal biotechnology, pp. 1931. New York, USA, Platinum Press.

Harsh NSK, Tiwari CK, Rai BK. 1996 - Forest fungi in the aid of tribal women of Madhya Pradesh, India. Sustainable Forestry 1, 10-15.

Hobbs C. 1986 - Medicinal Mushrooms: An exploration of traditional, healing and culture. Botanica Press, Santa Cruz. CA.

Ingleby K. 1999 - Scleroderma sinnamarense Mont. + Gnetum africanum Welw. Description of Ectomycorrhizae, 4, 127-133. 
Isaka M, Tanticharion M, Kongsaeree P, Thebtaranonth Y. 2001- Structures of cordypyridones A$\mathrm{D}$, antimalarial $\mathrm{N}$-hydroxy- and $\mathrm{N}$-methoxy-2-pyridones from the insect pathogenic fungus Cordyceps nipponica. Journal of Organic Chemistry, 66, 4803-4808.

Kanwal HK, Acharya K, Ramesh G, Reddy MS. 2011- Molecular Characterization of Morchella species from the Western Himalayan region of India. Current Microbiology 62(4), 1245-52.

Karwa A, Rai MK. 2010 - Tapping into the edible fungi biodiversity of Central India. Biodiversitas 11, 97-101.

Kaul TN. 1993 - Conservation of mushroom resources in India. Mushroom Research, 2, 11-18.

Kaul TN, Kachroo JL. 1974 - Common edible mushrooms of Jammu and Kashmir. Ind. Mush. Sci. 71, 26-31.

Kupra J, Anke T, Oberwinler G, Schramn G, Steglich W. 1979 - Antibiotics From basidiomycetes VII. Crinipellis stripitaria (Fr.) Pat. Journal of Antibiotics 32, 130-135.

Mizuno T, Saito H, Nishitoba T, Kawagishi H. 1995 - Antitumor active substances from mushrooms. Food Reviews International 111, 23-61.

Nautiyal S, Rao Maikhuri RK, KS, Saxena KG. 2001 - J. Herb. Spices Med. Plants 8, 47-64.

Phillips R. 2010 - Mushrooms and Other Fungi of North America. Firefly Books Ltd. New York.

Pradhan P, Banerjee S, Roy A, Acharya K. 2010 - Role of wild edible mushrooms in the Santal livelihood in lateritic region of West Bengal. J. Bot. Soc. Ben. 64(1), 61-65.

Purkayastha RP, Chandra A. 1985- Manual of Indian Edible Mushrooms. Today and Tomorrow's Printers and Publishers, New Delhi. p. 93.

Rai BK, Ayachi SS, Rai A. 1993 - A note on ethno-myco-medicines from Central India. Mycologist 7, 192-193.

Rammeloo J, Walleyn R. 1993 - The Edible Fungi of Africa South of the Sahara: A Literature Survey. Scripta Botanica Belgica 5, 1-62.

Sagar A, Chauhan A, Sehgal AK. 2005- Ethnobotanical study of some wild edible mushrooms of tribal district Kinnaur of Himachal Pradesh. Indian J. Mush. 23, 1-8.

Sanmee R, Tulloss RE, Lumyong P, Dell B, Lumyong S. 2008- Studies on Amanita (Basidiomycetes:Amanitaceae) in Northern Thailand. Fungal Diversity 32, 97-123.

Sarkar BB, Chakraborty DK, Bhattacharjee A. 1988- Wild edible mushroom flora of Tripura. Indian Agriculturist, 32, 139-143.

Semwal KC. 2003 - Systematics and Ecological Studies on the Genus Amanita from Garhwal Himalaya. Ph.D. thesis, H.N.B. Garhwal University (A Central University). Srinagar Garhwal, Uttarakhand, India.

Semwal KC, Bhatt RP, Upadhyay RC. 2005 - The Genus Amanita from Garhwal Himalaya region of India. Mushroom Research, 14 (2), 50-55.

Semwal KC, Bhatt RP, Upadhyay RC. 2006 - Occurrence and growth characters of Amanita spp. in Garhwal Himalaya. Indian Phytopath 59 (3), 309-313.

Singh N, Pathak R, Kathait AS, Rautela D, Dubey A. 2010 - Collection of Cordyceps sinensis (Berk.) Sacc. in the interior villages of Chamoli district in Garhwal Himalaya (Uttarakhand) and its Social Impacts. Journal of American Science 6 (6), 120-132.

Sharda RM, Kaushal SC, Negi GS. 1997 - Edible fungi of Garhwal-Himalaya. Mushroom Research 6, 11-14.

Sharma YK, Doshi A. 1996 - Some studies on an edible wild fungus Phellorinia inquinans, in Rajasthan, India. Mushroom Research, 5, 51-53.

Sharma S, Gautam AK, Bhadauria R. 2009 - Some important supplementary food plants and wild edible fungi of upper hilly region of district Shimla (Himachal Pradesh), India. Ethnobotanical Leaflets 13, 1020-28

Singh SK, Rawat GS. 2000 - Morel mushroom industry in India. Plant Talk 21, 36-37.

Smiley TE, Marx DH, Fraedrich BR. 1997 - Ectomycorrhizal fungus inoculation of established residential trees. Journal of Arboriculture 23(3), 113-115. 
Singer R. 1986 - Agaricales in Modern Taxonomy. (4th eds) Bishan Singh Mahendra Pal Singh, Dehradun, India. $981 \mathrm{pp}$

Suzuki H, Liyama K, Yoshida O, Yamazaki S, Yamamoto N, Toda S. 1990 - Structural characterization of the immunoactive and antiviral water-solubilized lignin in an extract of the culture medium of Lentinus edodes mycelia (LEM). Agric. Biol. Chem. 54, 479-487.

Wasson VP, Wasson RG. 1957 - Mushrooms, Russia and History. 2 vols. New York, Pantheon Books.

Yang ZL 1997 - Die Amanita-Arten von Südwestchina. Bibl Mycol 170, 1-240

Yang ZL, Doi Y. 1999 - A contribution to the knowledge of Amanita (Amanitaceae, Agaricales) in Japan. Bull Natl Sci. Mus., Tokyo, Ser. B 25 (3), 107-130

Yang ZL, Li TH 2001 - Notes on three white Amanitae of section Phalloideae (Amanitaceae) from China. Mycotaxon 78, 439-448. 